\title{
Mode I Interlaminar Fracture Behaviour and Mechanical Properties of CFRPs with Nanoclay Filled Epoxy Matrix
}

\author{
Naveed A. Siddiqui ${ }^{1,3}$, Ricky S.C. Woo ${ }^{1}$, Jang-Kyo Kim ${ }^{1 *}$, Christopher K.Y. Leung ${ }^{2}$ \\ and Arshad Munir ${ }^{3}$ \\ ${ }^{1}$ Department of Mechanical Engineering, ${ }^{2}$ Department of Civil Engineering \\ Hong Kong University of Science and Technology, Clear Water Bay, Hong Kong \\ ${ }^{3}$ National Engineering and Scientific Commission, P.O Box 2801, Islamabad, Pakistan.
}

\begin{abstract}
The Mechanical properties and fracture behavior of nanocomposites and carbon fiber composites (CFRPs) containing organoclay in the epoxy matrix have been investigated. Morphological studies using TEM and XRD revealed that the clay particles within the epoxy resin were intercalated or orderly exfoliated. The organoclay brought about a significant improvement in flexural modulus, especially in the first few wt\% of loading, and the improvement of flexural modulus was at the expense of a reduction in flexural strength. The quasi-static fracture toughness increased, whereas the impact fracture toughness dropped sharply with increasing the clay content.
\end{abstract}

Flexural properties of CFRPs containing organoclay modified epoxy matrix generally followed the trend similar to the epoxy nanocomposite although the variation was much smaller for the CFRPs. Both the initiation and propagation values of model I interlaminar fracture toughness of CFRP composites increased with increasing clay concentration. In particular, the propagation fracture toughness almost doubled with 7wt\% clay loading. A strong correlation was established between the fracture toughness of organoclay-modified epoxy matrix and the CFRP composite interlaminar fracture toughness.

Keywords: organoclay, nanocomposites, CFRP, modified epoxy composites, mode I delamination resistance

*Corresponding author: Tel) 852-2358 7207; Fax) 852-2358 1543; Email) mejkkim@ust.hk This is the Pre-Published Version 


\section{Introduction}

Polymer nanocomposites reinforced with nanoclay particles have attracted significant attention because of unique mechanical, thermal and physical properties along with excellent transport characteristics that are offered by the layered structure of clay particles with extremely high aspect ratios. A significant improvement of modulus provided by the exfoliated nanocomposite structure was first reported on clay-polyamide-6 composites, with $90 \%$ increase due to $4 \mathrm{wt} \%$ of exfoliated clay [1]. Remarkable ten-fold increases in strength and modulus were also reported with exfoliated organoclays in rubbery epoxy [2]. These property gains were at the expense of ductility, which decreased with increasing clay content [3]. In contrast, the reinforcement efficiency offered by the similar organoclay in glassy epoxy matrices was not as remarkable as in the rubbery epoxy, and the tensile strength often showed lower values than that of the neat epoxy [4]. However, reported results of fracture toughness of clay nanocomposites showed no apparent consensus. For example, almost a ten-fold reduction in fracture energy was reported for a polyamide nanocomposite containing $4 \mathrm{wt} \%$ of exfoliated clay [5], which was attributed to the reduction of plastic deformation in the constrained polymer matrix. Studies on brittle thermoset matrices indicated mixed results: the silane treated clay-polyester system [6] exhibited improved quasi-static fracture toughness, whereas the fracture properties of clay-glassy epoxy nanocomposites were little influenced by the exfoliated silicate layers [7].

Our previous study revealed [8,9] that both the moisture diffusivity and moisture 
permeability showed a systematic decrease with increasing clay content, which agreed with the prediction based on the simple tortuous path model. Increase in effective penetration path due to the very large aspect ratio of the silicate layers was responsible for the reduced permeability. The presence of organoclay in the epoxy matrix increased significantly the glass transition temperature, $T_{g}$, whether the nanocomposites were in a dry or wet condition. The organoclay was successfully treated with epoxy monomer to further improve the polar interactions with a poly(ethylene terephthalate-co-ethylene naphthalate) (PETN) matrix [10]. The morphological, thermal-mechanical, mechanical and gas barrier characteristics of the nanocomposites were evaluated using several characterization tools. It was found that the Cloisite 30B organoclay had better interactions with PETN and was more uniformly dispersed within PETN than the Cloisite 20A organoclay. Epoxy treatment of Cloisite 30B organoclay resulted in improvements in d-spacing between silicate layers, thermo-mechanical and tensile properties, as well as thermal stability, processing and gas barrier characteristics of the PETN/30B nanocomposites. These results suggest that the epoxy acted as the compatibilizer as well as the chain extender, improving the chemical interactions between PETN and organoclay, while discouraging the macromolecular mobility of polymer chains in the vicinity of clay particles

While a significant progress has been made on the development of clay reinforced polymers, only a few studies have been conducted on the use of the modified polymers as the matrix material for fibre reinforced composites. An earlier work presented two approaches for fabricating continuous carbon fiber nanocomposite containing organoclay modified epoxy 
matrices [11]. The incorporation of $2 \mathrm{wt} \%$ of organically modified montmorillonite (Cloisite 25) resulted in carbon-epoxy composite laminates with microcrack densities $50 \%$ lower than those in the unmodified materials under cryogenic cycling [12]. The flexural modulus was relatively unaffected, whereas the corresponding flexural strength was marginally reduced due to the $2 \mathrm{wt} \%$ of organoclay reinforcement. There was a maximum of 50\% improvement in initiation value of mode I interlaminar fracture toughness of unidirectional carbon-epoxy composites at an organoclay concentration of $7.5 w t \%$ in the matrix phase [13]. However, there were negligible changes in interlaminar shear strength due to the incorporation of organoclays.

This paper is continuation of our previous work [8-10], which is part of a larger project on clay-epoxy nanocomposites for applications as adhesive and matrix for fibre reinforced composites in the construction industries. Main objectives of this study were to develop organoclay-filled epoxy nanocomposites as the matrix for carbon fibre reinforced composite laminates, and to characterize the mechanical properties and fracture resistance of the hybrid composites. Failure mechanisms associated with the incorporated organoclay were identified. Correlations were established between the fracture properties of the nanocomposite matrix and the interlaminar fracture toughness of the hybrid laminate composite.

\section{Experiments}

\subsection{Fabrication of Nanocomposites and Composite Laminates}

The laminate composites were fabricated from carbon fibre plain woven fabric and 
organoclay-filled epoxy resin. The epoxy resin was a diglycidyl ether of bisphenol A (DGEBA) epoxy (Epon828, supplied by Shell Corp.). A eutectic mixture of 1,3-phenylenediamine (mPDA) and 4,4 methylenedianaline (MDA, both supplied by Aldrich) at a ratio of 40:60 by weight was used as curing agent. The addition of MDA was aimed to reduce the viscosity of the epoxy-hardener mixture without affecting the resultant composite properties. The low viscosity was necessary for hand lay-up of carbon fabric laminates. Plain woven carbon fibres (TI101 supplied by Taiwan electrical insulators Co.) with a unit weight of $200 \mathrm{~g} / \mathrm{m}^{2}$ was used as the main reinforcement for composite laminates. The material and processing conditions employed to prepare the organoclay nanocomposite was essentially the same as those reported previously [8-9]. The liquid epoxy was drawn into a beaker, which was heated to $75^{\circ} \mathrm{C}$ to lower the resin viscosity, and a desired amount of I30.P organoclay (octadecylamine modified montmorillonite, supplied by Nanocor.) was added into the resin. The I30P clay content was varied between $0,3,5$ and $7 \mathrm{wt} \%$ of epoxy resin. The resin and clay mixture was subjected to sonication using an ultrasonicator at an ultrahigh frequency (Programmable Ultrasonic Processor XL2020) for 12h, while maintaining the resin temperature at $75^{\circ} \mathrm{C}$ using an oil bath. The details of sonication power and duration were chosen after an extensive preliminary trial and error. The translucent color of the mixture after sonication indicates uniform distribution of organoclays, partly confirming the efficiency of the sonication conditions used. The mixture was outgassed in a vacuum oven, followed by addition of curing agent in 23wt\% of epoxy and stirring for 3min.

Ten ply laminates of $30 \mathrm{~cm}$ square were prepared by hand lay-up with all warp tows in the 
same direction on a steel mould plate. Necessary precautions were taken to keep fabrics well aligned. A $25 \mu \mathrm{m}$ thick Teflon release film was inserted in the mid-plane of the laminate at right angle to the warp direction as an initial crack for the mode I interlaminar fracture toughness test. The moulded laminates were wrapped with bleeders and peel plies within a Teflon dam all around, which was cured in a vacuum hot press (Technical Machine Product). The laminate was cured at $80^{\circ} \mathrm{C}$ for $2 \mathrm{hr}$ and at $150^{\circ} \mathrm{C}$ for $10 \mathrm{hr}$, followed by postcure at $160^{\circ} \mathrm{C}$ for $2 \mathrm{hr}$. The high curing temperature excursions for long durations were applied to make sure the resin was completely cured. A low pressure of $0.3 \mathrm{MPa}$ was applied for the first $10 \mathrm{hr}$ to maintain a constant fibre volume fraction of $21 \pm 1 \%$ and a uniform laminate thickness of $5.2 \pm 0.5 \mathrm{~mm}$. The laminates were cooled to room temperature before removal from the hot press.

To study the structural morphology of organoclay in the epoxy resin and to measure the flexural properties and fracture toughness of neat nanocomposites without carbon fibre reinforcement, a mixture was also prepared consisting of organoclay, epoxy and $14.5 \mathrm{wt} \%$ of mPDA curing agent. The mixture was cast into the flat mold having two matching aluminum plates and a Teflon dam of thickness $3.2 \mathrm{~mm}$ or $5.0 \mathrm{~mm}$ with an approximately square mould cavity. The nanocomposite was cured at $75^{\circ} \mathrm{C}$ for 3 h, followed by postcure at $125^{\circ} \mathrm{C}$ for $3 \mathrm{~h}$. The curing scheme was slightly different from that used for CFRP laminate fabrication where a small amount of MDA was added in the curing agent.

\subsection{Specimens and Mechanical Tests}


The morphology of organoclay was examined using a transmission electron microscope (TEM, JEOL 2010) to evaluate how well the clay reinforcements were dispersed within the epoxy matrix. TEM was performed at an operating voltage of $120 \mathrm{kV}$ on microtomed samples of thickness about $90 \mathrm{~nm}$. The fracture toughness of organoclay nanocomposites was also measured both under quasi-static and impact conditions using the compact tension and Izod impact tests, respectively. The compact tension and Izod impact specimens were prepared and tested according to the specifications, ASTM Standard D5045 and D256, respectively. The compact tension specimens were $50 \mathrm{~mm}$ wide $\mathrm{x} 48 \mathrm{~mm}$ high $\mathrm{x} 5 \mathrm{~mm}$ thick, and the initial crack length $\mathrm{a}=$ 20mm from the loading point (Figure 1(a)), which satisfied the dimensional requirements for the plane strain fracture condition. The Izod impact test specimens were $64 \mathrm{~mm}$ long x 12.7 wide $\mathrm{x}$ $3.2 \mathrm{~mm}$ thick, and the notch depth was $10.2 \mathrm{~mm}$. The notch tips were sharpened with a fresh razor blade. The compact tension test was performed on a universal testing machine (MTS Sintech 10/D) at a cross-head $10 \mathrm{~mm} / \mathrm{min}$. The maximum load, $\mathrm{P}_{c}$, was recorded when the specimen fractured, from which the stress intensity factor, $\mathrm{K}_{\mathrm{IC}}$, under the plain strain conditions was calculated using the following equation:

$$
K_{\text {IC }}=\frac{P_{c}}{b \sqrt{W}} f\left(\frac{a}{W}\right)
$$

where

$$
f\left(\frac{a}{W}\right)=\frac{\left(2+\frac{a}{W}\right)\left[\left(0.886+4.64\left(\frac{a}{W}\right)-13.32\left(\frac{a}{W}\right)^{2}+14.72\left(\frac{a}{W}\right)^{3}-5.6\left(\frac{a}{W}\right)^{4}\right]\right.}{\left(1-\frac{a}{W}\right)^{3 / 2}}
$$

and $\mathrm{W}=40 \mathrm{~mm}$ and the specimen thickness $\mathrm{b}=5 \mathrm{~mm}$. The corresponding critical strain energy 
release rate, $\mathrm{G}_{\mathrm{IC}}$, was determined as follows:

$$
G_{I C}=\frac{U}{b W \Phi}
$$

where $U$ and $\Phi$ are defined as:

$$
\begin{gathered}
U=\frac{1}{2} P_{\max }\left[u_{\max }-u_{i}\right] \\
\Phi=\frac{\left(1.9118+19.118 x-2.5122 x^{2}-23.226 x^{3}+20.54 x^{4}\right)(1-x)}{\left(19.118-5.0244 x-69.678 x^{2}+82.16 x^{3}\right)(1-x)+2\left(1.9118+19.118 x-2.5112 x^{2}-23.226 x^{3}+20.54 x^{4}\right)}
\end{gathered}
$$

where $\mathrm{x}=\mathrm{a} / \mathrm{W}$. $\mathrm{u}_{\max }$ is the displacement corresponding to the maximum load $\mathrm{P}_{\max }$, and $\mathrm{u}_{\mathrm{i}} \mathrm{is}$ the corresponding displacement for an un-notched specimen. $U$ is the therefore the corrected integration over the load-displacement curve.

The Izod test was performed on an impact tester (Tinius Olsen Model 92T) at a speed of the pendulum tip $3.434 \mathrm{~m} / \mathrm{s}$ when impacted. The impact fracture toughness was calculated from the impact energy absorbed to break the specimen divided by the cross sectional ligament area of the specimen. A minimum of four and ten specimens were tested for each set of conditions with specimens containing varying clay contents, respectively, for the compact tension and Izod impact tests.

The mechanical properties of clay nanocomposites and carbon fibre laminate composites were measured in three-point flexural test according to the specification, ASTM Standard D 790-96, using 120mm long x 20mm wide x 3mm thick specimens cut from the moulded plates. The mode I interlaminar fracture toughness of composite laminates was measured using the double cantilever beam (DCB) test. Specimens of $150 \mathrm{~mm}$ long x $22.5 \mathrm{~mm}$ wide were cut from 
the composites plates, to the end of which a pair of aluminum tabs were bonded using an epoxy adhesive. The details of specimen dimensions and initial crack are shown in Figure 1(b). The DCB specimen edges were polished and a thin layer of white brittle paint was applied. Fine lines at an interval of $2 \mathrm{~mm}$ were scribed to help monitor the advancing crack tip during the test. The initial crack length was $42.5 \pm 1 \mathrm{~mm}$. The flexural and DCB tests were conducted on a universal testing machine (MTS 858) at a cross-head speed of $1.75 \mathrm{~mm} / \mathrm{min}$ and $1.0 \mathrm{~mm} / \mathrm{min}$, respectively, under ambient condition. At least five and three specimens were tested for set of conditions, respectively. In the DCB test, the loads, $P$, and the corresponding displacements, $\delta$, were recorded for a series of crack lengths, $a$. The mode I interlaminar fracture toughness, $\mathrm{G}_{\mathrm{Ic}}$, was calculated using the modified beam theory according to the specification, ASTM Standard D 5528, taking into account the rotation at the delamination front:

$$
G_{I C}=\frac{3 P \delta}{2 b(a+|\Delta|)}
$$

where $b$ is the specimen width $(=22.5 \mathrm{~mm})$. Compliance, $\mathrm{C}$, values were calculated from the load-displacement data obtained from the typical loading and unloading curves. The intercepts, $\Delta$, with the abscissa were determined experimentally from the least square plots of cubic root of compliance, $\mathrm{C}^{1 / 3}$, against the crack length, $a$, for the individual specimen (see Figure 11). At least five flexure and three DCB samples were tested for a given set of conditions. The DCB fracture surfaces were examined using a scanning electron microscope (Joel 6300).

\section{Results and Discussion}




\subsection{Morphologies and mechanical properties of clay-epoxy nanocomposites}

Typical TEM photographs of nanocomposites containing 5wt\% clay are presented in Figure 2, indicating that the I30P organoclays were well dispersed within the epoxy with a mixture of exfoliation and intercalation. The interlayer distance estimated from the TEM photograph gave a measurement larger than 10nm, which is consistent with our previous morphological study based the X-ray diffraction (XRD) and TEM analyses [9]. The basal (001) reflection appeared at $3.7^{\circ}$ for the I30P organoclay with an inherently larger interlayer distance of 2.38nm than other types of organoclays, such as KH-MT and Cloisite 20A. After mixing with epoxy resin, the (001) reflection shifted to $2.6^{\circ}$ with a swollen interlayer distance of $3.39 \mathrm{~nm}$, as shown in Figure 3 . Upon cure, the (001) reflection further shifted towards a lower angle beyond the capacity of the instrument, suggesting that orderly exfoliation and/or large intercalation occurred during reaction with the amine hardener. The estimated d-spacing after cure was at least $4.4 \mathrm{~nm}$.

The flexural properties of epoxy nanocomposite with different clay loadings are presented in Figure 4, and the corresponding quasi-static and impact fracture toughness values are shown in

Figure 5. The increment of clay concentration brought about a significant improvement in flexural modulus, especially in the first few wt\% of clay loading: an increase of $26 \%$ was registered with the addition of 3wt\% clay. The diminishing improvement in flexural modulus at high clay contents is attributed to the higher possibility of forming unwanted agglomerates, which in turn reduced the reinforcing efficiency of clay. The improvements of flexural modulus were at the expense of reductions in flexural strength (Figure 4(b)). The clay agglomerates and/or 
non-uniformly distributed clays may present at high clay contents, and these agglomerates can act as crack initiation sites, causing the nanocomposite to fail prematurely at a low failure stress/strain. It was also suggested that different cure speeds between the bulk epoxy and the silicate interfaces may induce internal stresses, leading to a substantial loss of strength [14].

It is interesting to note from Figure 5 that there was a direct or inverse relationship between the fracture toughness and clay concentration, depending on the loading rate. The quasi-static fracture toughness increased nearly $60 \%$ with the addition of 3wt $\%$ clay, but there was no further significance improvement afterwards up to $7 \mathrm{wt} \%$ clay. In contrast, there was a sharp drop of nearly $45 \%$ in impact fracture toughness when $1 \mathrm{wt} \%$ clay was added into the epoxy, followed by little variation with further increasing the clay content.

The SEM photographs of the corresponding fracture surfaces taken near the initial crack tip are shown in Figures 6 and 7. The neat resin samples in quasi-static fracture exhibited a smooth and featureless surface representing brittle failure of a homogeneous material (Figure 6(a)), whereas the corresponding impact fracture samples showed substantial plastic deformation with associated shear lips along the crack propagation direction (Figure 7(a)). The nanocomposites containing clays also presented different fracture morphologies depending on the loading mode. Well-bonded and rather uniformly distributed clay agglomerates in different sizes are clearly seen, which were responsible for the enhancement or reduction in fracture toughness. No visible interfacial debonds were observed between the agglomerates and the epoxy matrix, indicating a strong interfacial adhesion for all samples studied. For the quasi-static fracture specimens, there 
were many river markings near the clay agglomerates, a reflection that cracks propagated around the agglomerates taking a long path and allowing toughening mechanisms, such as pinning and crack tip bifurcations, to occur [15]. While the river markings became more extensive and deeper at high clay concentrations (Figures 6(b) to 6(d)), there were only marginal increases in quasi-static fracture toughness, because the clay agglomerates tended to become larger in size with increasing the clay content. If the agglomerate sizes are unnecessarily large, they could be fractured more easily without providing effective barrier for pinning and bifurcation of the advancing cracks. The implication of this observation is that a low content of clay already led to a large improvement in quasi-static fracture toughness of nanocomposites and higher clay contents did not help further improvements.

The failure mechanisms in the impact specimens were somehow different from those of the quasi-static fracture specimens. The SEM photographs (Figures 7 (b) to (d)) indicate that the clay agglomerates, loosely-bonded weak silicate layer bundles, became brittle under the high strain rate loading and acted as stress concentrators in the matrix [16], which can fracture easily even before the cracks reached the surrounding matrix material. Although some tails and river markings were visible (especially in Figure 7 (b)), the pinning and crack tip bifurcations mechanisms were less evident under the impact condition than in quasi-static loading, indicating their contributions to composite toughness were much smaller. Some voids were present in the vicinity of organoclay agglomerates (Figure 7 (b)), which are detrimental to impact fracture performance. The rough fracture surface alone did not provide enough fracture resistance. This 
situation is rather different from that of the particulate composites made from micrometer-scale particles, such as $\mathrm{SiO}_{2}$ or $\mathrm{Al}_{2} \mathrm{O}_{3}$. For example, the Charpy impact fracture toughness of $\mathrm{SiO}_{2}$ reinforced epoxy composites was shown much higher than that of a neat epoxy resin depending on the testing temperature [17].

\subsection{Flexural properties of CFRP composites}

Flexural properties of the CFRP composites with and without organoclays are listed in Table 1. Because the carbon fibre contents were slightly different between composite plates reinforced with different clay contents, the flexural properties were normalized with carbon fibre volume fraction of $20 \%$ and are presented in Figure 8 . Within the data scattering, the flexural modulus increased whereas the flexural strength marginally decreased with increasing clay content, although the variations were relatively small compared to the other properties. Because the carbon fibre content, staking sequence and curing parameters were all kept the same, the changes in flexural properties of CFRP should be directly related to the matrix properties which were influenced by the dispersion, morphology and content of clay. Judging from the fact that the flexural properties of the clay-epoxy nanocomposite (Figure 4) and the CFRP composites (Figure 8) varied similarly with respect to clay content, it is clear that the changes in matrix properties controlled the small, but apparent changes in CFRP flexural properties. Nevertheless, there were only $9.8 \%$ and $5.0 \%$ corresponding variations in flexural modulus and strength of CFRP laminates, respectively, although the matrix flexural properties were changed by $35.9 \%$ and 
$12.7 \%$, respectively, due to $7 \mathrm{wt} \%$ clay content. This was expected because the matrix material could make much smaller contributions to the mechanical properties of the hybrid composite than the stiffer/stronger carbon fabric reinforcement although the matrix volume fraction (80\%) was much higher than the fibre.

In addition to the direct influence of matrix properties, the carbon fibre-matrix interfacial properties are another important factor that is adversely affected by the presence of organoclay in epoxy. It was shown recently [18] that the incorporation of layered silicates into a polyamide matrix reduced the glass fibre-polyamide matrix interfacial adhesion, as measured by the critical transfer length using the fibre fragmentation test. The presence of nanoparticles was seen as having a negative effect on composite mechanical properties through premature interfacial debonding. It appears that clay agglomerates are particularly detrimental to the fibre-matrix interfacial adhesion, which has a more significant influence on the composite strength than on composite modulus [19].

\subsection{Mode I interlaminar fracture toughness}

Typical load-extension curves obtained from the DCB tests of CFRP composites are presented in

Figure 9. The load increased linearly until it reached the maximum where the crack initiated, which is followed by a gradual decrease as the crack further propagated. There were characteristic stick-slips in all cases due to the variations in local material properties, such as resin-rich or fiber-rich regions along the longitudinal direction, misalignment of the fibers and 
voids, as well as the fracture of bridged fibres or fibre bundles [20]. The material variations cannot be completely avoided although care was taken in the hand lay-up composite fabrication process. The composites containing organoclay in the epoxy exhibited much longer maximum extensions at complete fracture than those with neat epoxy matrix (Figure 9), suggesting more stable crack growth behavior for the former composites. This observation is further manifested by the load-extension curves obtained after loading and unloading excursions, as shown in Figure 10, confirming the higher resistance to fracture with increasing the clay content in the matrix.

The mode I interlaminar fracture toughness, $\mathrm{G}_{\mathrm{IC}}$, was calculated using Equation (1). The correction factor, $\Delta$, was determined from the least square plots of cubic root of compliance, $\mathrm{C}^{1 / 3}$, against the crack length, $a$, for the individual specimen. Figure 11 indicates that $\Delta$ was typically about $5 \mathrm{~mm}$ for all materials studied. The crack growth resistance curves of $\mathrm{G}_{\mathrm{IC}}$ are compared amongst the CFRP composites with different clay contents, as shown in Figure 12. There was significant crack growth resistance for all materials studied. In particular, the propagation $\mathrm{G}_{\mathrm{IC}}$ values of the CFRPs with 3 to $7 \mathrm{wt} \%$ clay contents were almost twice those of corresponding $\mathrm{G}_{\mathrm{IC}}$ initiation values. Both the initiation and propagation $\mathrm{G}_{\mathrm{IC}}$ values increased in general with increasing the clay concentration. This observation is consistent with previous reports [13] for a similar unidirectional carbon fibre epoxy composites in that the initiation values of mode I interlaminar fracture toughness increased gradually with increasing clay content up to $7.5 \mathrm{wt} \%$.

With reference to the fracture surface morphologies shown in Figure 13, several important 
mechanisms are identified, which were responsible for the improved interlaminar fracture resistance in the CFRP composites containing organoclays. The composite made from neat epoxy showed a smooth river line structure which is characteristic of brittle epoxy, and the strongly bonded fibre-matrix interface. The hybrid CFRP composite samples containing nanoclay in the matrix typically presented rougher matrix surface than those with neat epoxy, resulting from the pinning and crack tip bifurcation, as discussed above (Figures 6(b) to (d)). Debonding or delamination along the fibre direction was also clearly seen, a reflection of locally weak fibre-matrix interfacial adhesion, which is consistent with a recent finding [18]. In CFRP composites made from brittle matrices, such as the epoxy resins with and without organoclay used in this study, the multilayer delaminations may be beneficial in creating a large fracture process zone size through the fibre bridging mechanism in the wake of the advancing crack tip. It was shown previously for similar CFRP composites [20] that microcracks grew at local weak spots to form multi-plane cracks before merging with the main crack, which in turn increased the mode I interlaminar fracture toughness. These CFRP composites were made from epoxy matrices modified with liquid rubber, alumina particles, alumina short fibres or their combinations.

\subsection{Correlation between matrix properties and composite interlaminar properties}

It is well known [21] that the interlaminar fracture toughness of carbon fibre polymer matrix composites is determined many factors, including matrix strength and ductility, fibre-matrix interfacial adhesion, laminate configuration, presence of pores and residual stress state, amongst 
which the matrix ductility or fracture toughness is one of the most dominant material parameters. Strong correlations have been reported [21] between the matrix toughness, $\mathrm{G}_{\mathrm{IC}}{ }^{\mathrm{m}}$, and the composite mode I interlaminar fracture toughness, $\mathrm{G}_{\mathrm{IC}}{ }^{\mathrm{c}}$. An established view is that i) for matrix $\mathrm{G}_{\mathrm{IC}}{ }^{\mathrm{m}}$ lower than about $0.5 \mathrm{~kJ} / \mathrm{m}^{2}$, the composite $\mathrm{G}_{\mathrm{IC}}{ }^{\mathrm{c}}$ is greater than the matrix $\mathrm{G}_{\mathrm{IC}}{ }^{\mathrm{m}}$ and there is approximately linear correlation between these toughness values; ii) as the matrix $\mathrm{G}_{\mathrm{IC}}{ }^{\mathrm{m}}$ increases above $0.5 \mathrm{~kJ} / \mathrm{m}^{2}$, the incremental increase in the composite $\mathrm{G}_{\mathrm{IC}}{ }^{\mathrm{c}}$ is much smaller than the matrix $\mathrm{G}_{\mathrm{IC}}{ }^{\mathrm{m}}$; and iii) for matrix $\mathrm{G}_{\mathrm{IC}}{ }^{\mathrm{m}}$ above $2.0 \mathrm{~kJ} / \mathrm{m}^{2}$, there is little gain in the composite $\mathrm{G}_{\mathrm{IC}}{ }^{\mathrm{c}}$.

To evaluate any correlation between these properties, the composites $\mathrm{G}_{\mathrm{IC}}{ }^{\mathrm{c}}$ is plotted as a function of matrix $\mathrm{G}_{\mathrm{IC}}{ }^{\mathrm{m}}$ in Figure 14. The mean $\mathrm{G}_{\mathrm{IC}}{ }^{\mathrm{c}}$ values and one standard deviation were taken from Figure 12 as the steady-state propagation values. The quasi-static $\mathrm{G}_{\mathrm{IC}}{ }^{\mathrm{m}}$ values were calculated using Equation (3) based on the compact tension test. Also included in this plot are the mode I propagation interlaminar fracture toughness data taken from our previous study [20] for similar CFRP composites with modified epoxy matrices. Figure 14 indicates that the current experimental results fall reasonably well within the already established trend of the $\mathrm{G}_{\mathrm{IC}}{ }^{\mathrm{m}}-\mathrm{G}_{\mathrm{IC}}{ }^{\mathrm{c}}$ relationship for similar CFRP composites containing epoxy matrices modified with other types of reinforcement, such as liquid rubber, alumina particles and short fibres. It is clearly seen that the improved static toughness of epoxy matrix due to the addition of organoclay is directly translated to improved composite interlaminar fracture toughness.

\section{Conclusions}


The mechanical and fracture properties are studied of organoclay modified epoxy nanocomposites, as well as the CFRP composite made therefrom. The following conclusions can be highlighted from the study.

1) The organoclay brought about a significant improvement in flexural modulus: an increase of $26 \%$ was registered with the addition of 3wt\% clay. The flexural strength gradually decreased with increase in clay content.

2) There was a direct or inverse relationship between the fracture toughness and clay concentration, depending on the loading rate. The quasi-static fracture toughness increased about $60 \%$ with the addition of $3 w t \%$ clay, and further increase in clay content was not beneficial to fracture toughness. There was a large drop of nearly $45 \%$ in impact fracture toughness with only $1 \mathrm{wt} \%$ clay, followed by little variation with further increasing the clay content.

3) The flexural properties of CFRP composites generally followed the trends against clay concentration, similar to the matrix nanocomposites. The modulus increased while the strength decreased marginally with increase in clay content.

4) The organoclay modified epoxy gave rise to significant improvements in both crack growth resistance and fracture toughness of mode I interlaminar fracture of CFRP composites. Both the initiation and propagation $\mathrm{G}_{\mathrm{IC}}$ values of CFRP composites increased with increasing clay content: in particular, the propagation fracture toughness almost doubled with $7 \mathrm{wt} \%$ clay loading.

5) There was a strongly correlation found between the static fracture toughness $\mathrm{G}_{\mathrm{IC}}{ }^{\mathrm{m}}$ of organoclay-modified epoxy and the interlaminar fracture toughness $\mathrm{G}_{\mathrm{IC}}{ }^{\mathrm{c}}$ of CFRP composites. The data obtained in this study also fell within the well-established general trend for other CFRP composites, partly confirming the validity of test results. 


\section{Acknowledgements}

This project was supported by the Research Grant Council of Hong Kong Special Administration Region (Project Number HKUST6184/03E). Part of the experiments was carried out when NS was a visiting scholar at Hong Kong University of Science \& Technology (HKUST) from the National Engineering and Scientific Commission of Pakistan. Assistance with experiments by $\mathrm{Mr}$ Alexander Wieser as an exchange student from the Technical University of Munich, Germany is much appreciated. Technical assistance from the Advanced Engineering Materials Facility (AEMF) and Materials Characterization and Preparation Facilities (MCPF), HKUST is also appreciated.

\section{References}

[1] Okada A, Kawasumi M, Usuki A, Kojima Y, Kurouchi T and Kamigaito O, "Nylon 6-clay hybrid” Mat. Res. Soc. Proc. 171 (1990) 45-50.

[2] Lan T and Pinnavaia TJ, “Clay reinforced epoxy nanocomposites” Chem Mater. 6 (1994) 2216-2219.

[3] Lee DC and Jang LW, “Characterization of epoxy-clay hybrid composite prepared by emulsion polymerization” J. Appl. Polym. Sci. 68 (1998) 1997-2005.

[4] Lan T, Kaviratna PD and Pinnavaia TJ, "Mechanism of clay tactoid exfoliation in epoxy-clay nanocomposites” Chem Mater. 7 (1995) 2144-2150.

[5] Harcup JP and Yee AF, "Deformation and fracture of polymer silicate layer nanocomposites” ANTEC’99 Conf. Proc. 3 (1999) 3396-3398.

[6] Kornmann X, Berglund LA, Sterte J and Giannelis EP, "Nanocomposites based on montmorillonite and unsaturated polyester” Polym. Eng. Sci. 38 (1998) 1351-1358. 
[7] Kornmann X, Lindberg $\mathrm{H}$ and Berglund LA, "Synthesis of epoxy-clay nanocomposites: influence of the nature of the clay on structure” Polymer 42 (2001) 1303-1310.

[8] Kim JK, Hu CG, Woo RSC and Sham ML, "Moisture barrier characteristics of organoclay-epoxy nanocomposites” Compos. Sci. Technol. 65 (2005) 805-813.

[9] Hu CG and Kim JK, “Epoxy-organoclay nanocomposites: morphology, moisture absorption behavior and thermo-mechanical properties” Compos. Interfaces, 12 (2005) 271-289.

[10] Lai MF and Kim JK, "Effects of epoxy treatment of organoclay on structure, thermo-mechanical and transport properties of poly(ethylene terephthalate-co-ethylene naphthalate) / organoclay nanocomposites” Polymer 46 (2005) 4722-2734.

[11] Rice BP, Chen C, Cloos L, Curliss D. Carbon fiber composites prepared from organoclay-aerospace epoxy nonocomposites. In:46th International SAMPE Symposium and Exhibition, Long Beach, CA; 2001. pp. 355-61.

[12] Timmermn JF, Hayes BS, Seferis JC, "Nanoclay reinforcement effects on the cryogenic micro cracking of carbon fiber/epoxy composites” Compos. Sci. Technol. 62 (2002) 1249-1258.

[13] Becker O, Varley RJ and Simon JP, “Use of layered silicates to supplementarily toughen high performance epoxy-carbon fiber composites” J. Mater. Sci. Lett., 22 (2003) 1411-1414.

[14] Zilg C., Thomann R., Finter J., and Mülhaupt R., “The influence of silicate modification and compatibilizers on mechanical properties and morphology of anhydride-cured epoxy nanocomposites”, Macromol. Mater. Eng., 280/281 (2000) 41-46.

[15] Liu W, Hoa SV and Pugh M,’Organoclay-modified high performance epoxy composites” Compos. Sci Technol. 65 (2005) 307-316.

[16] Wetzel B., Haupert F. and Zhang M. Q., "Epoxy Nanocomposites with high mechanical and tribological performance”, Compos. Sci. Technol., 63 (2003) 2055-2067.

[17] Koh SW, Kim JK and Mai YW, "Fracture toughness and failure mechanisms in silica-filled epoxy resin composites: effect of temperature and loading rate" Polymer, 34 (1993) 3446-3455.

[18] Vlasveld DPN, Parlevliet PP, Bersee HEN and Picken SJ, Fibre-matrix adhesion in glass-fibre reinforced polyamide-6 silicate nanocomposites, Composite Parts A, 36 (2004) 1-11. 
[19] Kim JK and Mai YW, "High strength, high fracture toughness fibre composites with interface control-a review" Compos. Sci. Technol., 41 (1991) 333-378.

[20] Kim JK, Baillie C, Poh J and Mai YW, "Fracture toughness of CFRP with modified epoxy matrices" Compos. Sci. Technol., 43 (1992) 283-297.

[21] Kim JK and Mai YW, Engineered Interfaces in Fiber Reinforced Composites, Elsevier, New York, 1998. pp. 330-342.

[22] Bradley WL, "Understanding the translation of neat resin toughness into delamination toughness in composites” Key Eng. Mater. 37 (1989) 161-198. 
Table 1. Flexural properties of CFRP without and with organoclay reinforcements.

\begin{tabular}{llllll}
$\begin{array}{l}\text { Matrix } \\
\text { (Clay } \\
\text { content) }\end{array}$ & $\begin{array}{l}\text { Carbon fiber } \\
\text { Content } \\
(\text { vol \%) }\end{array}$ & $\begin{array}{l}\text { Flexural } \\
\text { strength } \\
(\mathrm{M} \mathrm{Pa})\end{array}$ & $\begin{array}{l}\text { Normalized } \\
\text { strength } \\
(\mathrm{M} \mathrm{Pa})\end{array}$ & $\begin{array}{l}\text { Flexural } \\
\text { modulus } \\
(\mathrm{G} \mathrm{Pa})\end{array}$ & $\begin{array}{l}\text { Normalized } \\
\text { modulus } \\
(\mathrm{G} \mathrm{Pa})\end{array}$ \\
\hline $0 \%$ & 22.1 & $401.2 \pm 23$ & $363.0 \pm 21.3$ & $19.0 \pm .9$ & $17.2 \pm 0.7$ \\
$3 \%$ & 22.3 & $385.1 \pm 22.8$ & $345.4 \pm 21.4$ & $19.4 \pm 1.2$ & $17.5 \pm 1.1$ \\
$5 \%$ & 20.5 & $330.9 \pm 44$ & $323.9 \pm 43.8$ & $18.5 \pm 1.1$ & $18.1 \pm 1.1$ \\
$7 \%$ & 21.2 & $365.4 \pm 20.5$ & $344.7 \pm 19.4$ & $20.0 \pm 1.5$ & $18.9 \pm 1.4$ \\
\hline
\end{tabular}




\section{Figure Captions}

Figure 1 Geometry and dimensions of (a) compact tension (CT) and (b) double cantilever beam (DCB) specimens.

Figure 2 Typical TEM photographs of nanocomposites containing $5 w t \%$ clay at (a) low and (b) high magnifications.

Figure 3 XRD spectra for (a) I30P organoclay, (b) mixture of clay and epoxy, and (c) clay nanocomposites after cure. After Hu and Kim [9].

Figure 4 Flexural properties of organoclay reinforced epoxy nanocomposites as a function of clay content

Figure 5 (a) quasi-static and (b) Izod impact fracture toughness of organoclay reinforced epoxy nanocomposites as a function of clay content.

Figure 6 SEM photographs of quasi-static fracture surfaces of organoclay-epoxy nanocomposites containing different clay contents: (a) $0 \mathrm{wt} \%$ (b) $3 \mathrm{wt} \%$ (c) $5 \mathrm{wt} \%$ and (c) $7 \mathrm{wt} \%$.

Figure 7 SEM photographs of Izod impact fracture surfaces of organoclay-epoxy nanocomposites containing different clay contents: (a) $0 \mathrm{wt} \%$ (b) $3 \mathrm{wt} \%$ (c) $5 \mathrm{wt} \%$ and (c) $7 \mathrm{wt} \%$.

Figure 8 Flexural properties of CFRP composites plotted as a function of clay content.

Figure 9 Typical load-extension curves of DCB specimens made from CFRP composites with different clay contents.

Figure 10 Load-extension curves of DCB specimens with clay contents of (a) 0 wt\% and (b) 3 wt\%, obtained after loading and unloading excursions.

Figure 11 Compliance calibration curves of DCB specimens made from CFRP composites with different clay contents: (a) $0 \mathrm{wt} \%$; (b) $3 \mathrm{wt} \%$; (c) $5 \mathrm{wt} \%$ and (d) $7 \mathrm{wt} \%$.

Figure 12 Mode I interlaminar fracture toughness, $\mathrm{G}_{\mathrm{IC}}$, as a function of crack length, a, for CFRP composites containing different clay contents.

Figure 13 SEM photographs of DCB fracture surfaces for CFRP composites with different clay contents: (a) $0 w t \%$ (b) $3 w t \%$ (c) $5 w t \%$.

Figure 14 Correlation between the composite interlaminar fracture toughness, $\mathrm{G}_{\mathrm{IC}}{ }^{\mathrm{c}}$, and the matrix fracture toughness, $\mathrm{G}_{\mathrm{IC}}{ }^{\mathrm{m}}$. 


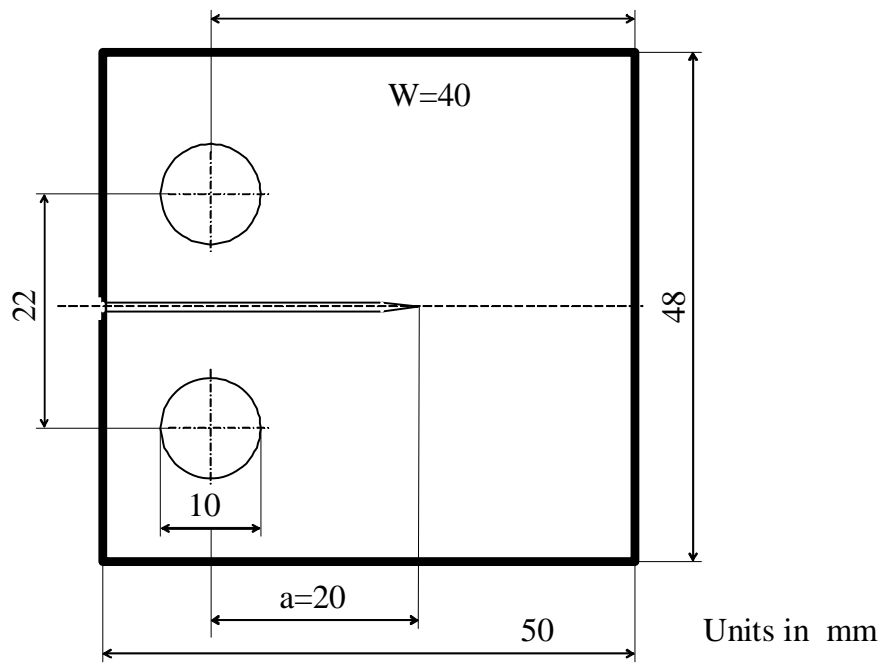

(a)

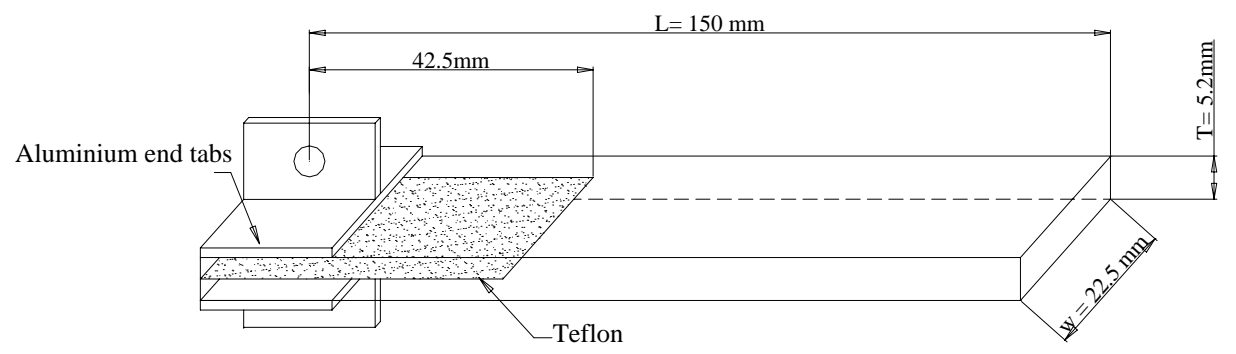

(b)

Figure 1 Geometry and dimensions of (a) compact tension (CT) and (b) double cantilever beam (DCB) specimens. 


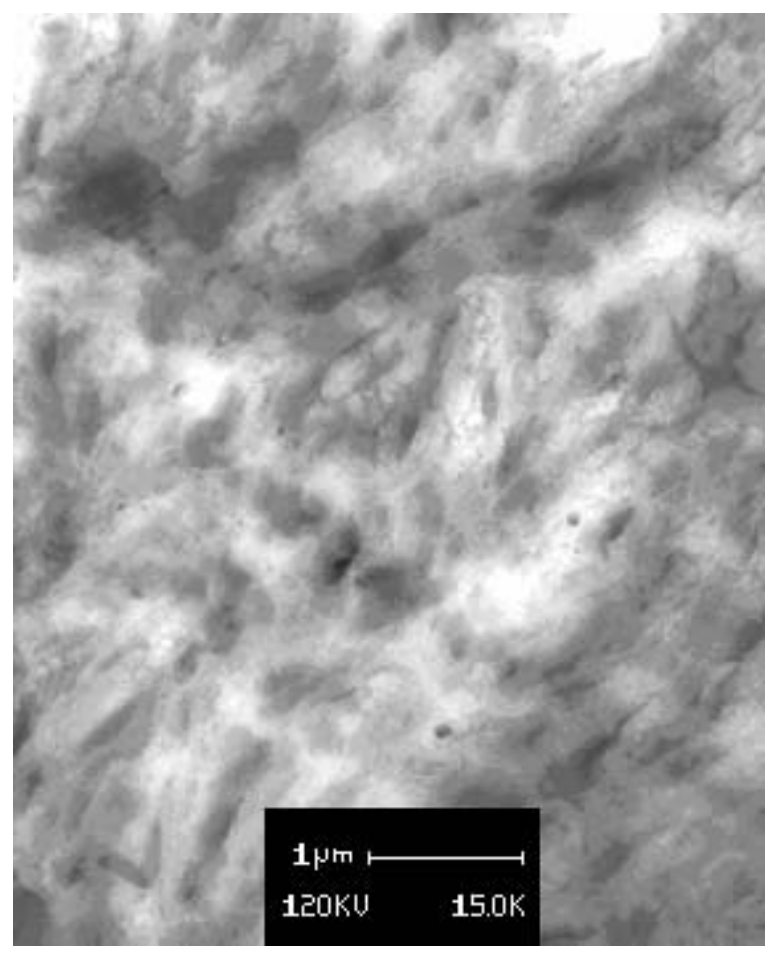

(a)

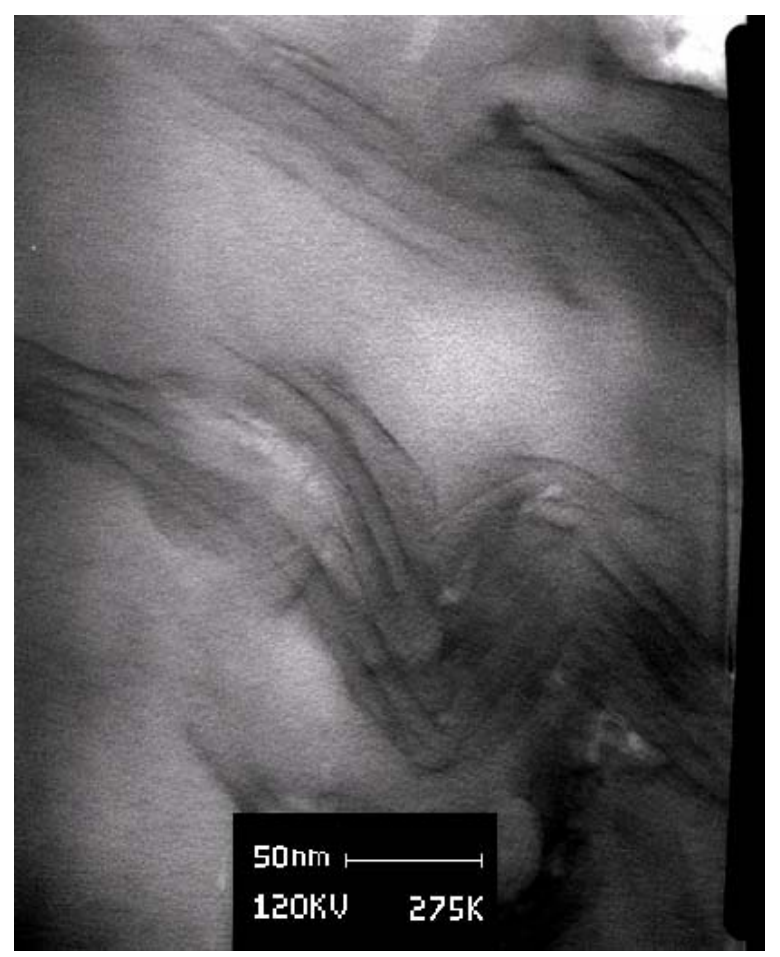

(b)

Figure 2 Typical TEM photographs of nanocomposites containing 5wt \% clay at (a) low and (b) high magnifications.

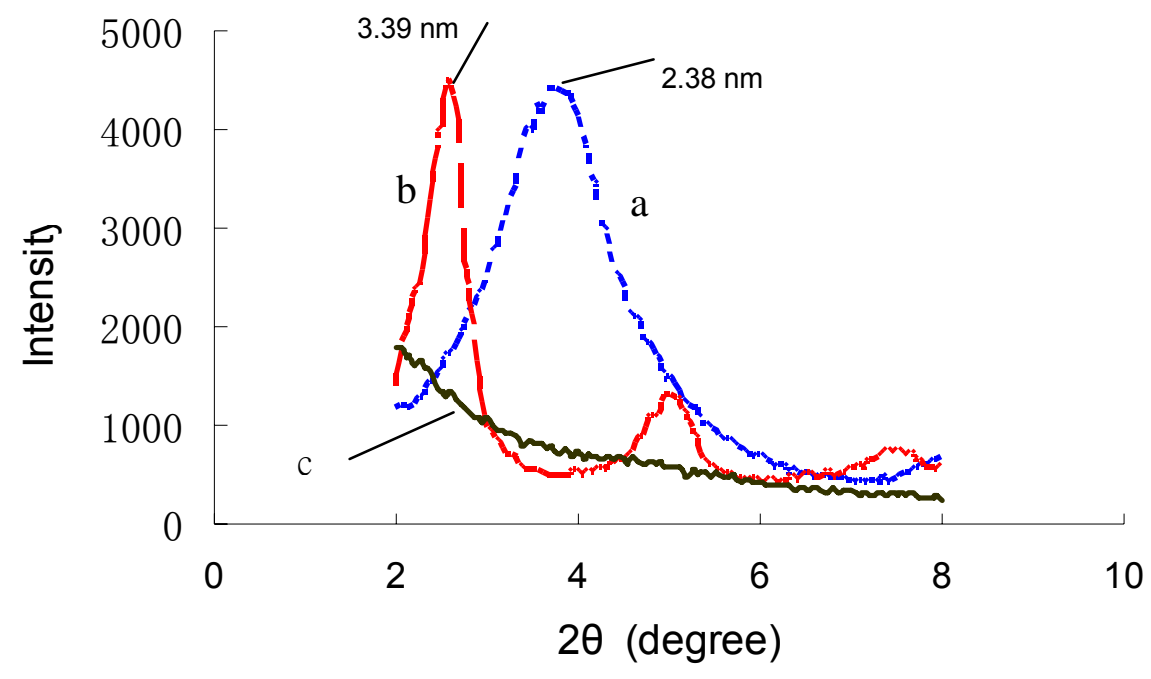

Figure 3 XRD spectra for (a) I30P organoclay, (b) mixture of clay and epoxy, and (c) clay nanocomposites after cure. After Hu and Kim [9]. 


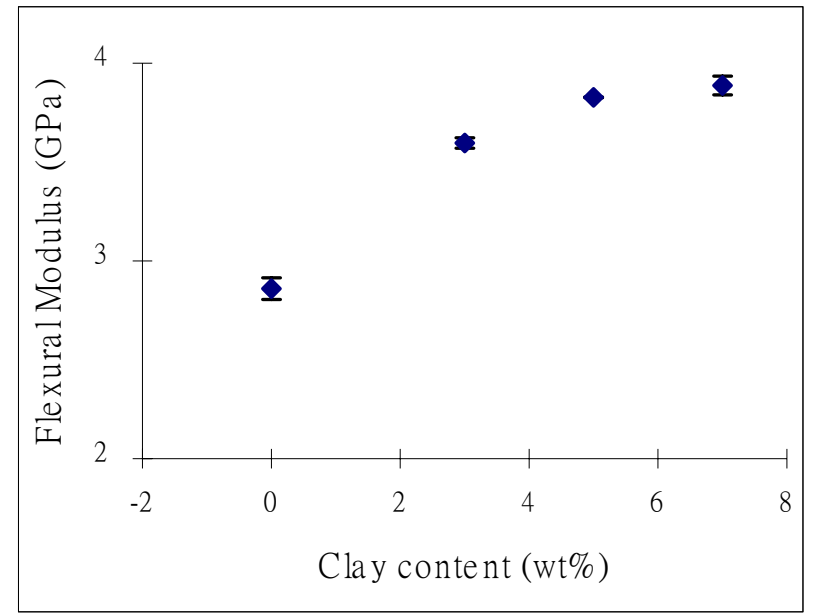

(a)

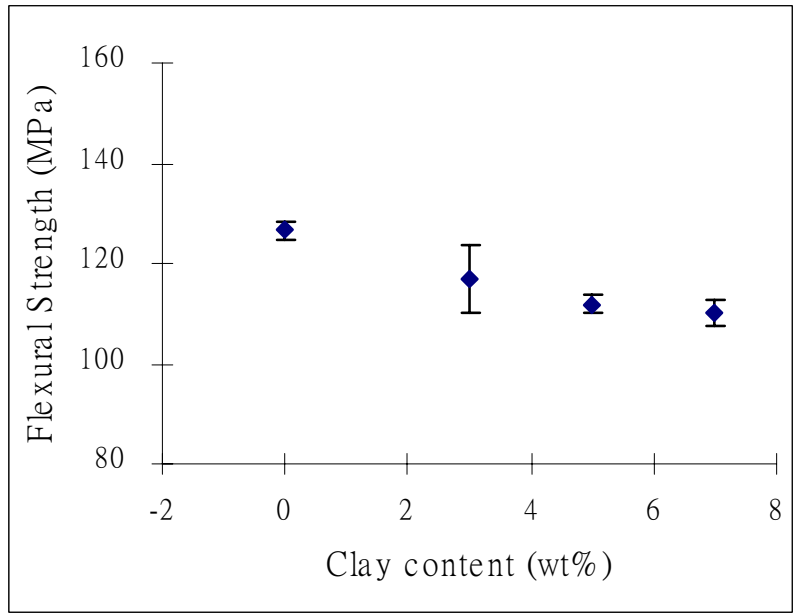

(b)

Figure 4. Flexural properties of organoclay reinforced epoxy nanocomposites as a function of clay content.

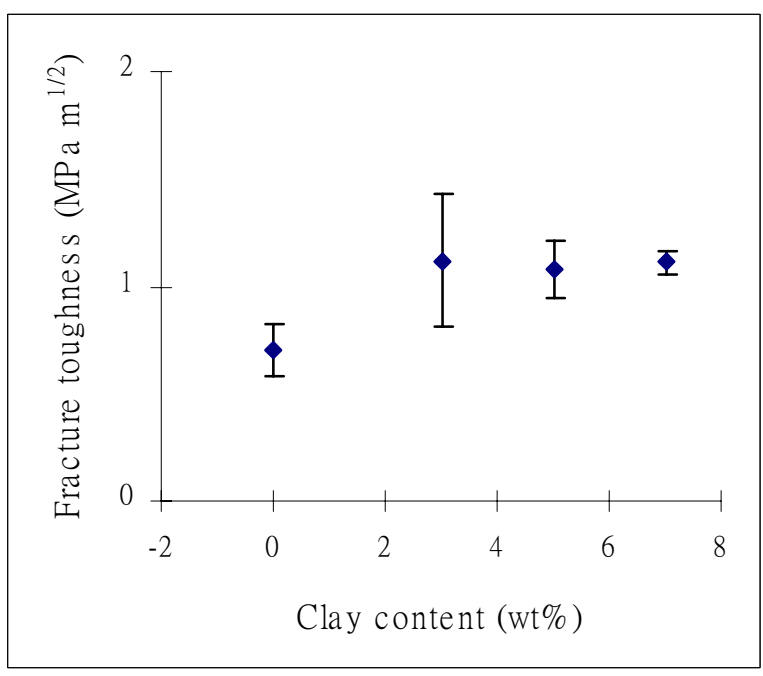

(a)

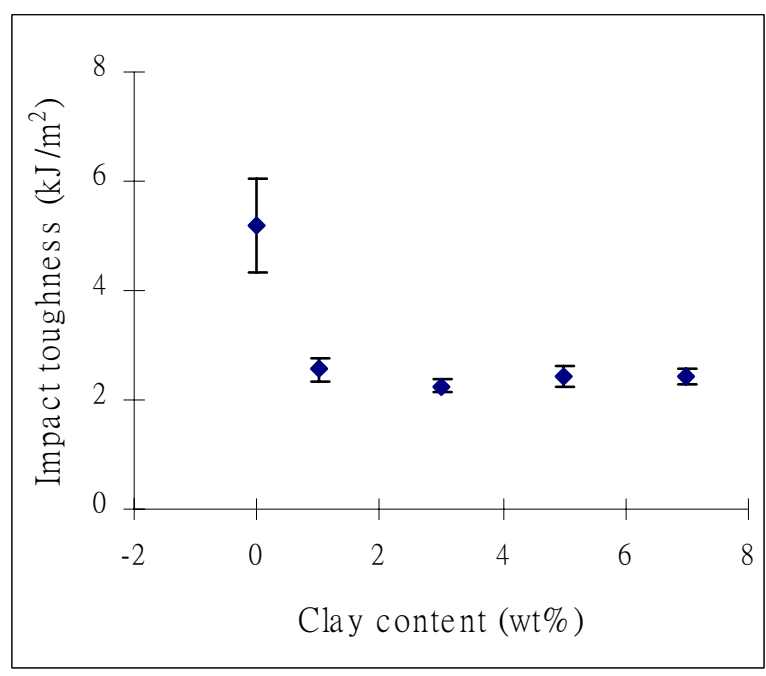

(b)

Figure 5. (a) quasi-static and (b) Izod impact fracture toughness of organoclay reinforced epoxy nanocomposites as a function of clay content. 

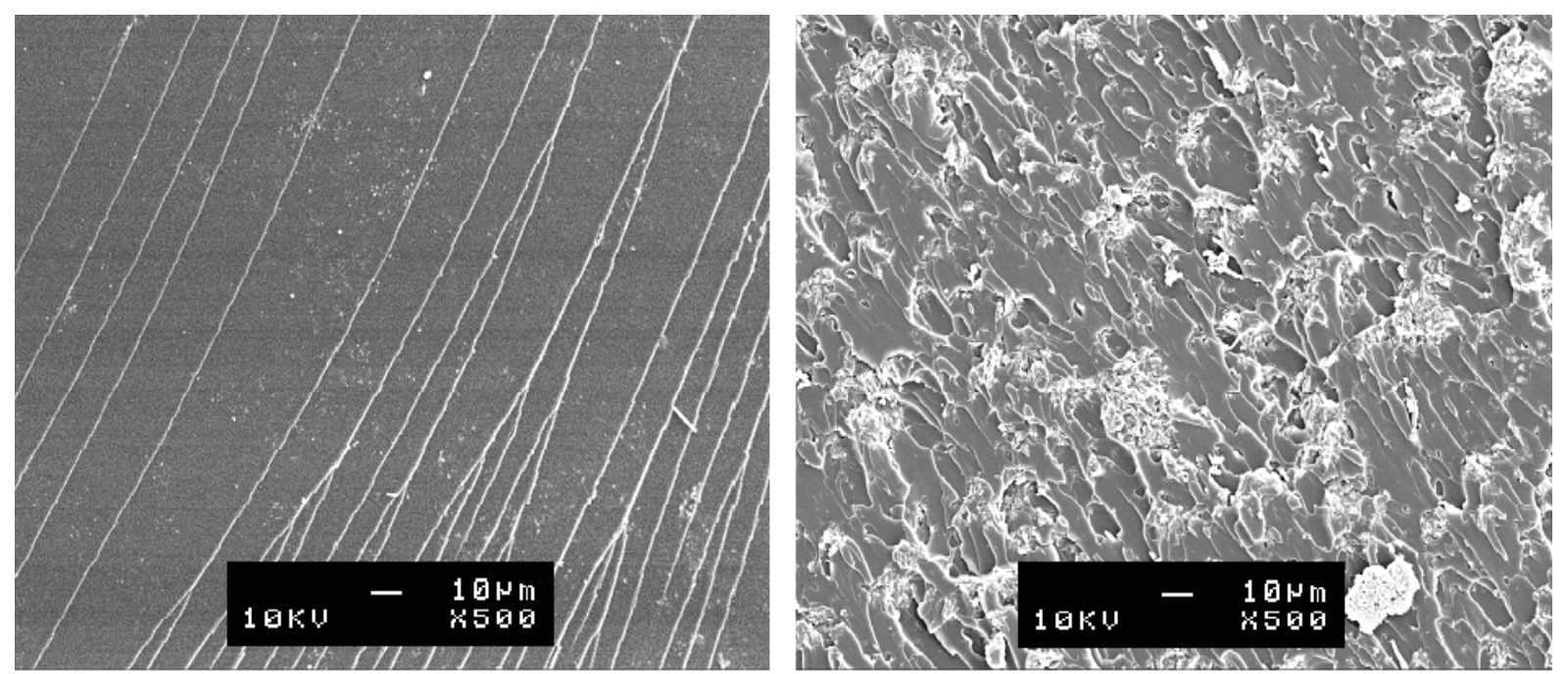

(a)

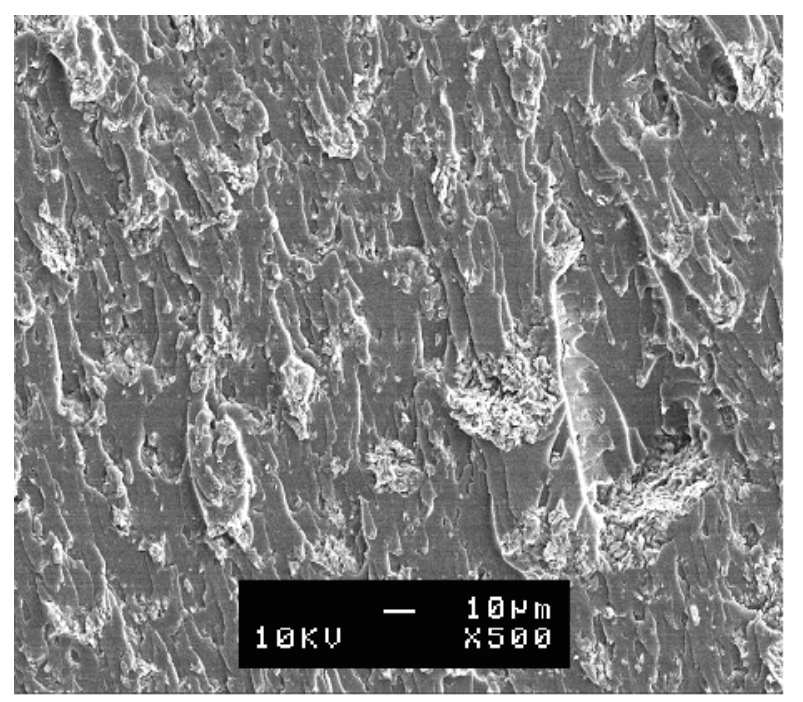

(c) (b)

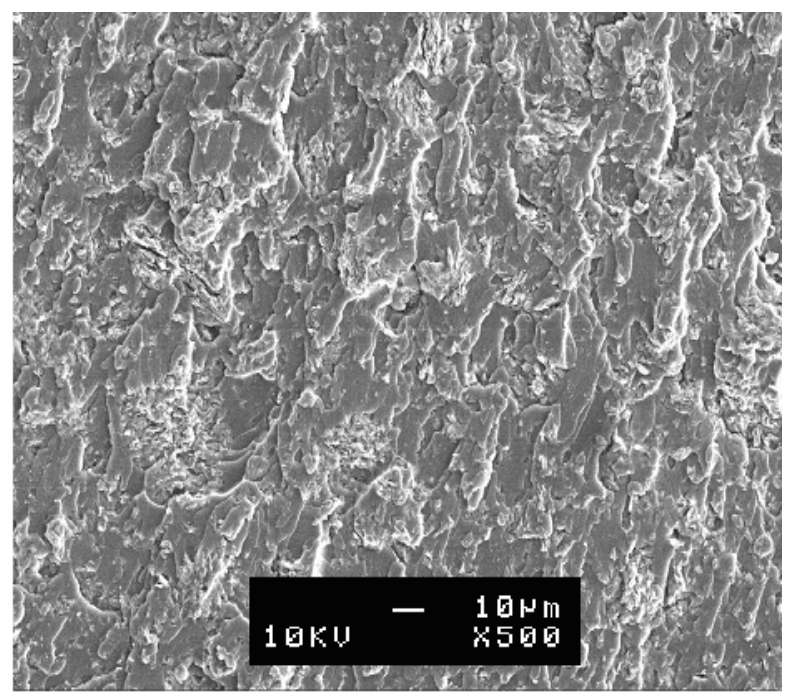

(d)

Figure 6. SEM photographs of quasi-static fracture surfaces of organoclay-epoxy nanocomposites containing different clay contents: (a) $0 \mathrm{wt} \%$ (b) $3 \mathrm{wt} \%$ (c) $5 \mathrm{wt} \%$ and (c) 7 wt\%. 


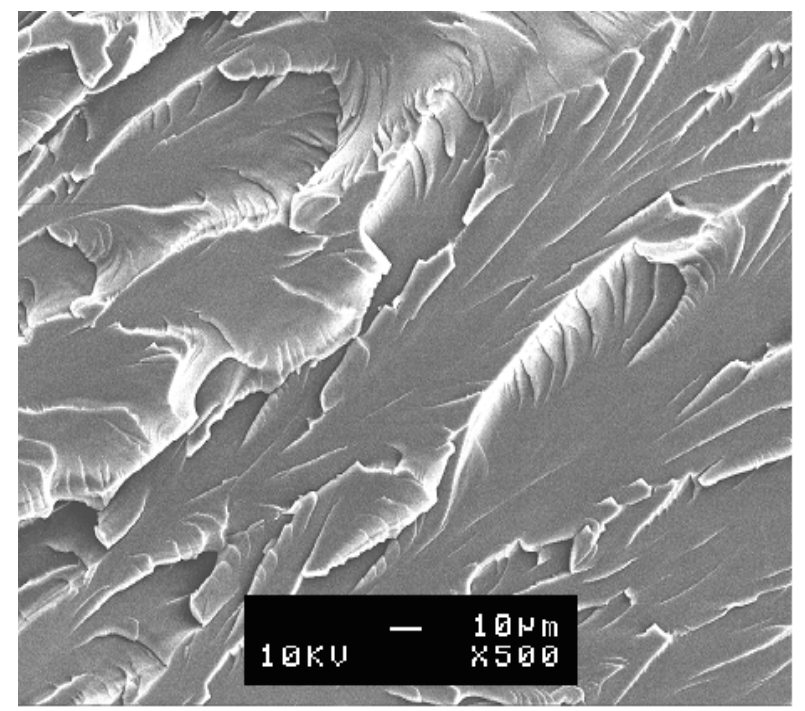

(a)

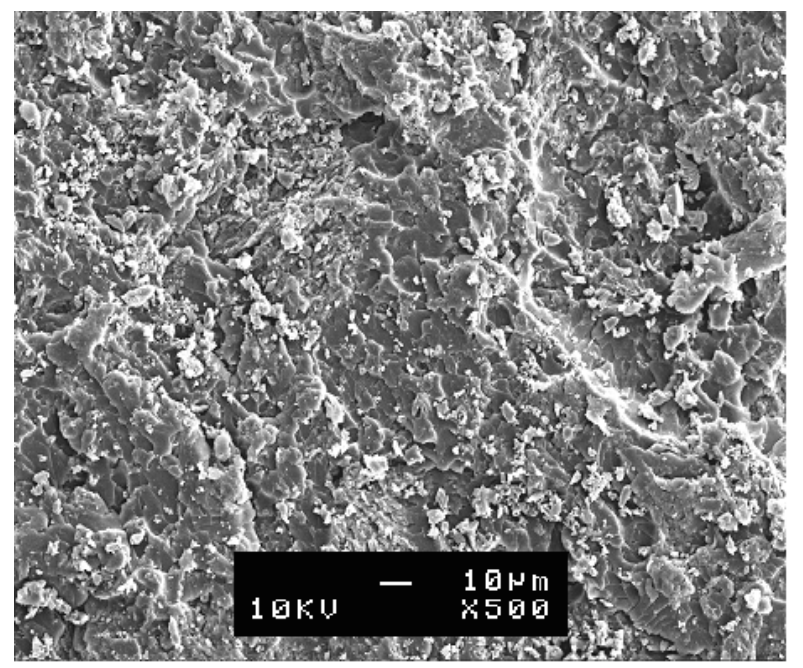

(c)

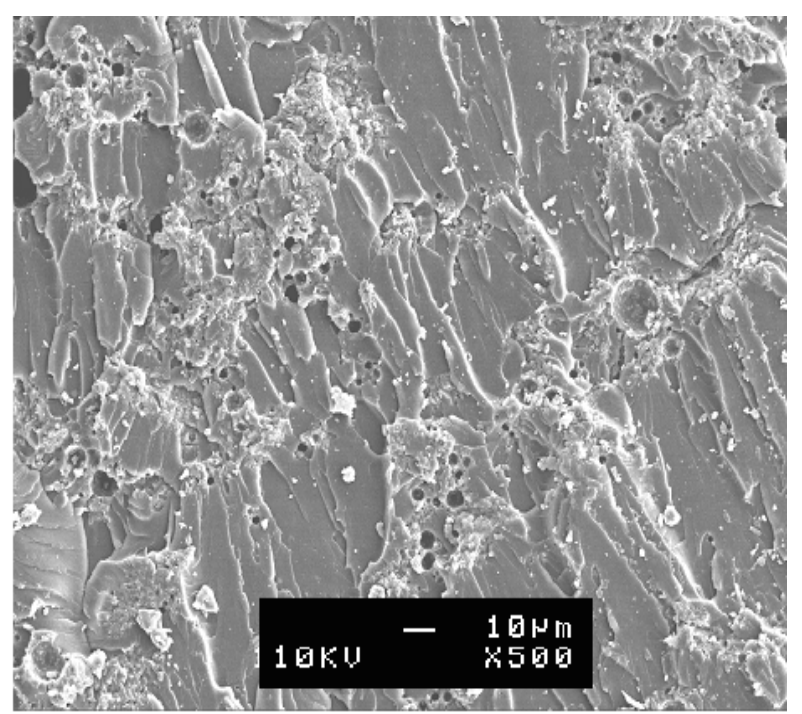

(b)

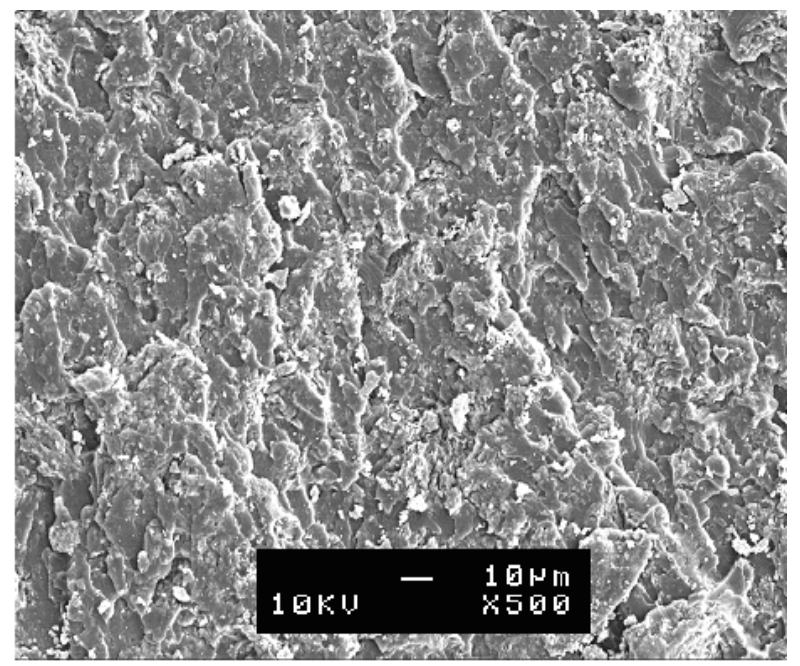

(d)

Figure 7. SEM photographs of Izod impact fracture surfaces of organoclay-epoxy nanocomposites containing different clay contents: (a) $0 \mathrm{wt} \%$ (b) $3 \mathrm{wt} \%$ (c) $5 \mathrm{wt} \%$ and (c) $7 \mathrm{wt} \%$ 


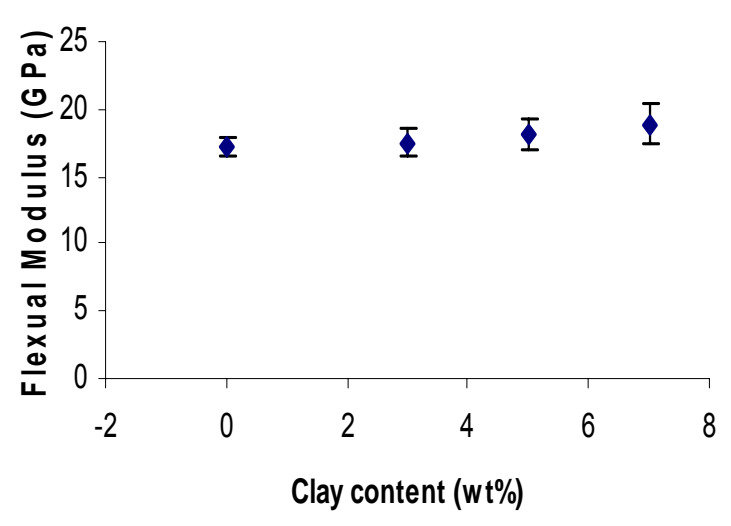

(a)

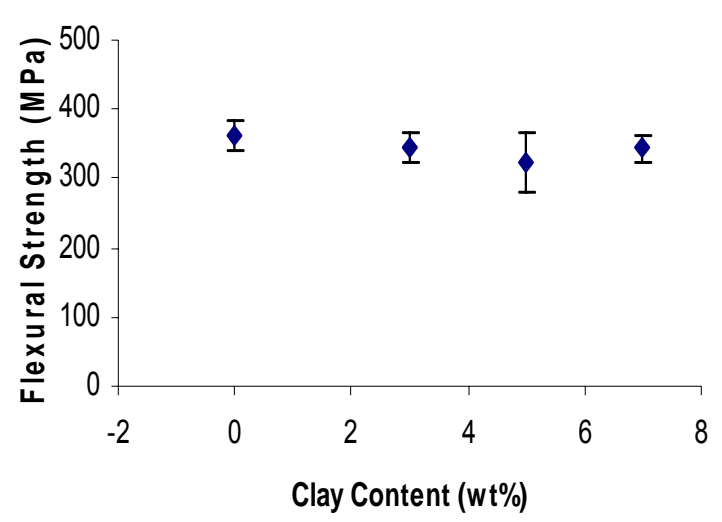

(b)

Figure 8. Flexural properties of CFRP composites plotted as a function of clay content.

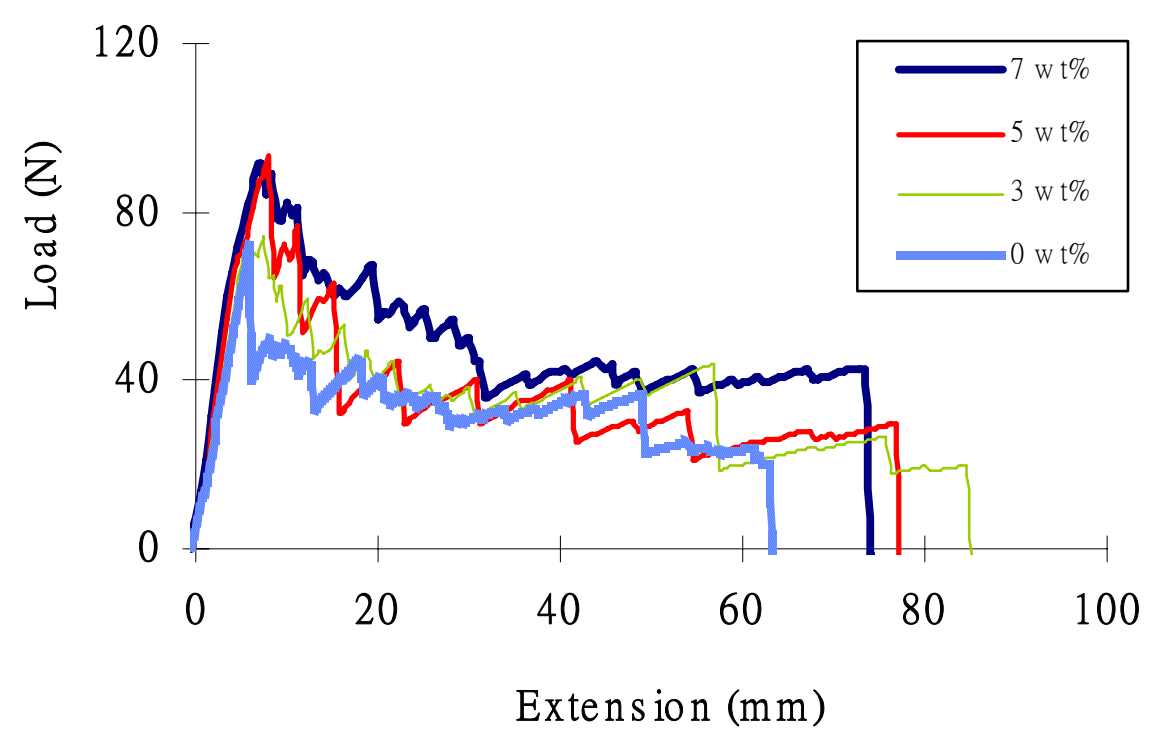

Figure 9. Typical load-extension curves of DCB specimens made from CFRP composites with different clay contents. 


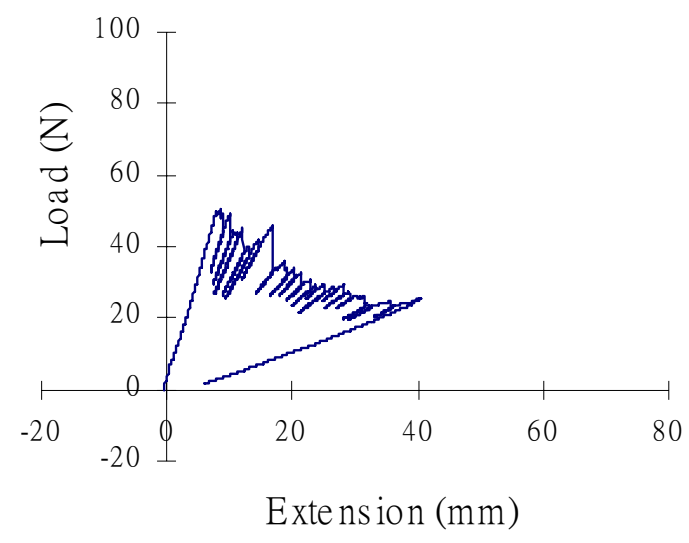

(a)

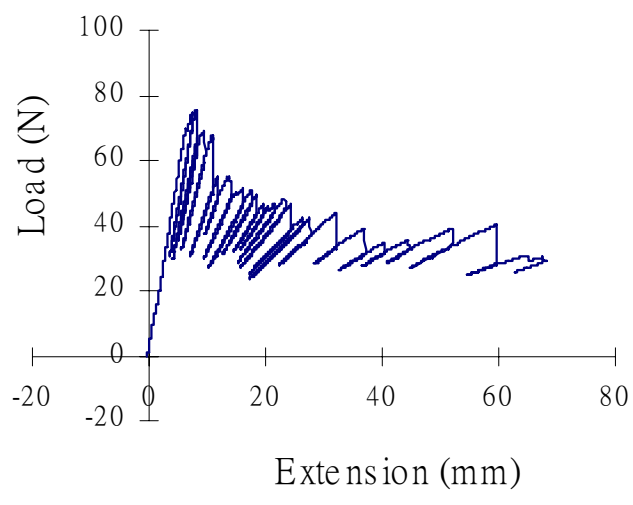

(b)

Figure 10. Load-extension curves of DCB specimens with clay contents of (a) $0 \mathrm{wt} \%$ and (b) 3 $\mathrm{wt} \%$, obtained after loading and unloading excursions. 


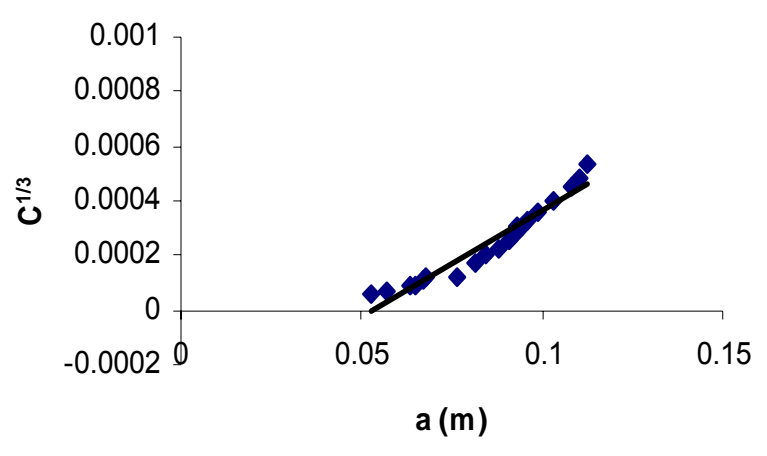

(a)

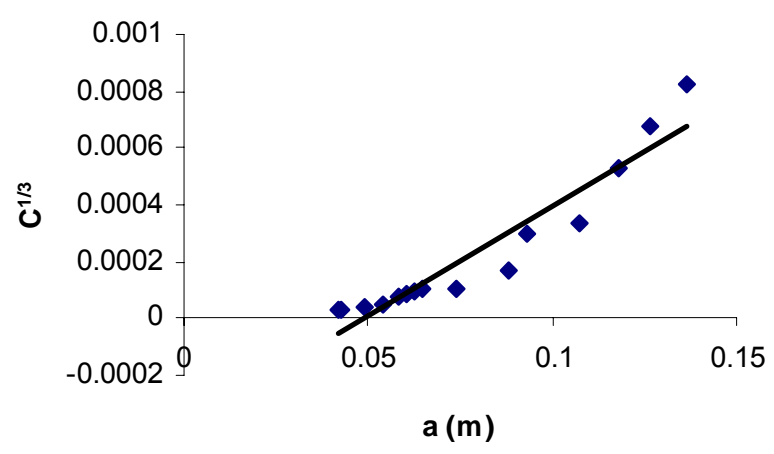

(c)

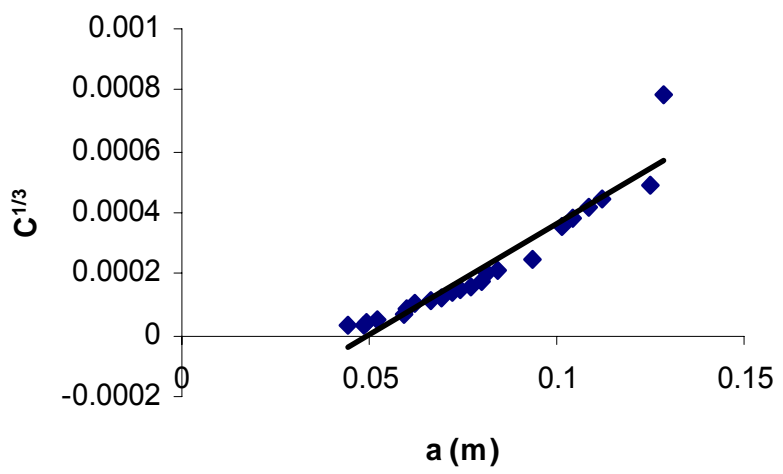

(b)

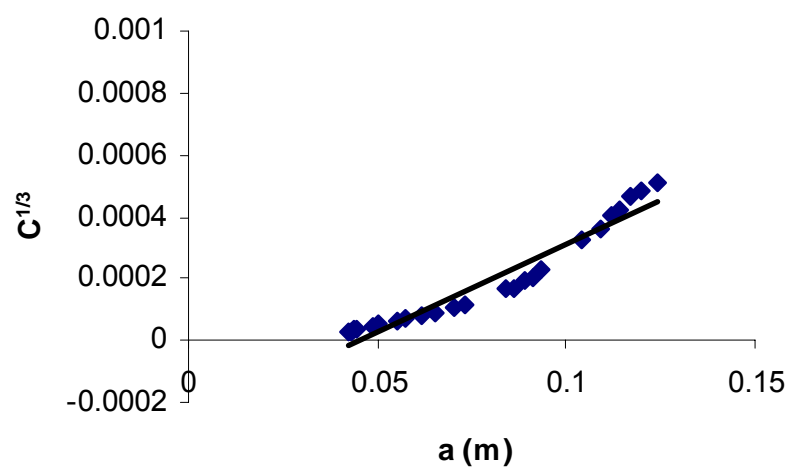

(d)

Figure 11. Compliance calibration curves of DCB specimens made from CFRP composites with different clay contents: (a) $0 \mathrm{wt} \%$; (b) $3 \mathrm{wt} \%$; (c) $5 \mathrm{wt} \%$ and (d) $7 \mathrm{wt} \%$. 


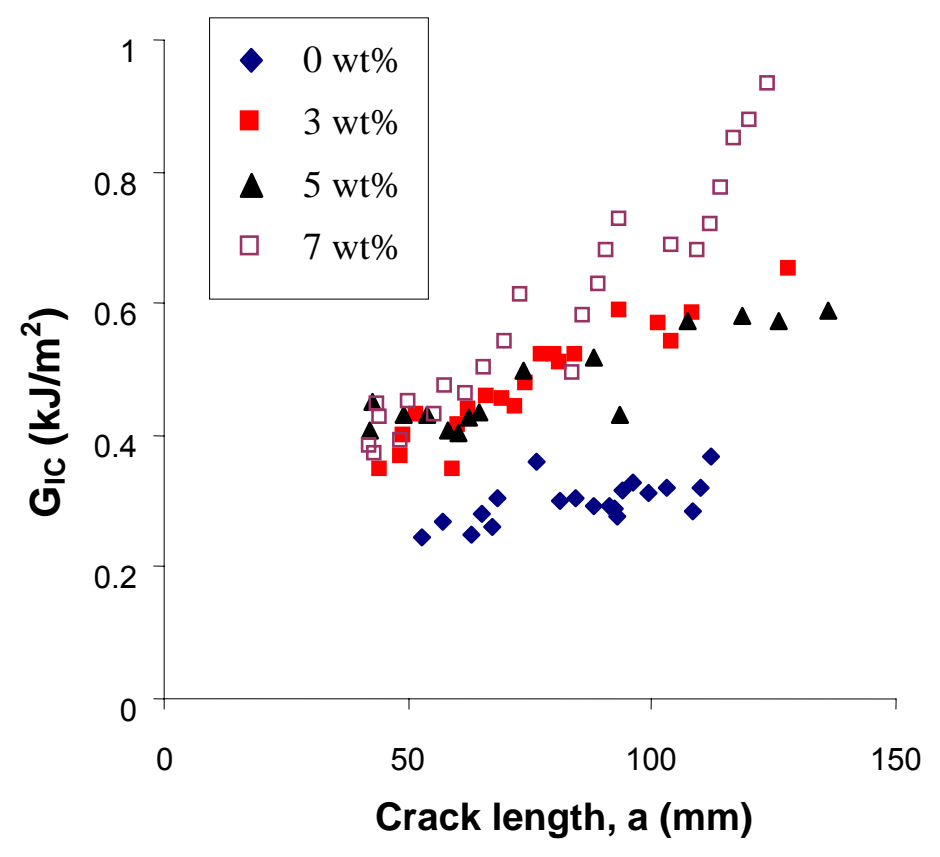

Figure 12. Mode I interlaminar fracture toughness, $\mathrm{G}_{\mathrm{IC}}$, as a function of crack length, a, for CFRP composites containing different clay contents. 


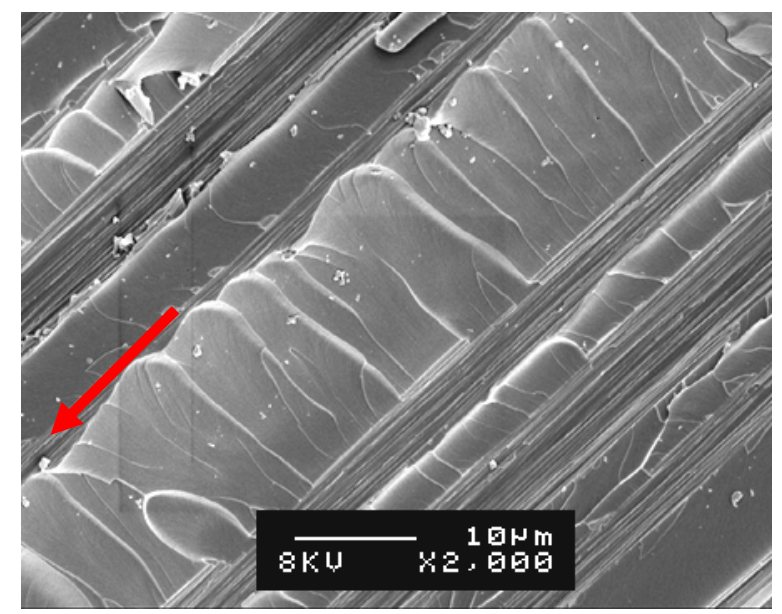

(a)

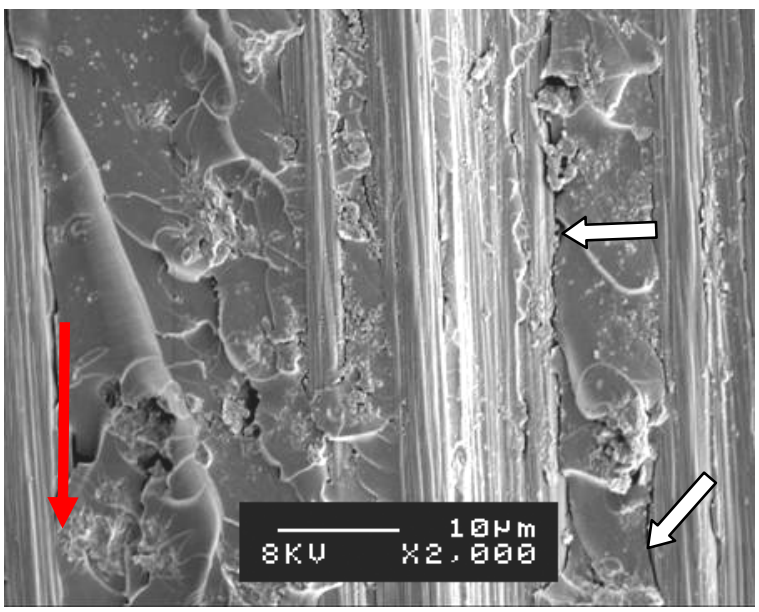

(b)

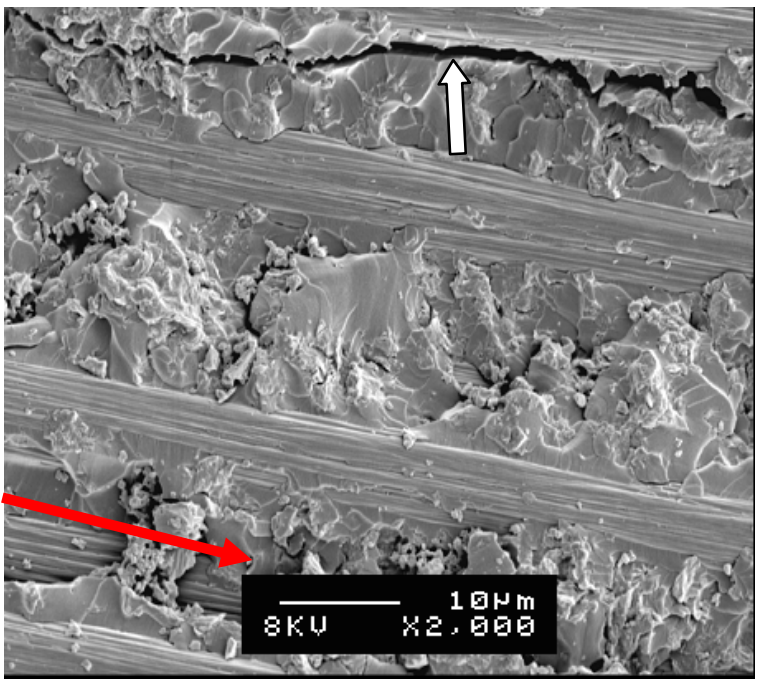

(c)

Figure 13. SEM photographs of DCB fracture surfaces for CFRP composites with different clay contents: (a) 0wt\% (b) 3wt\% (c) 5wt\%. Long arrows indicate the direction of crack propagation. 


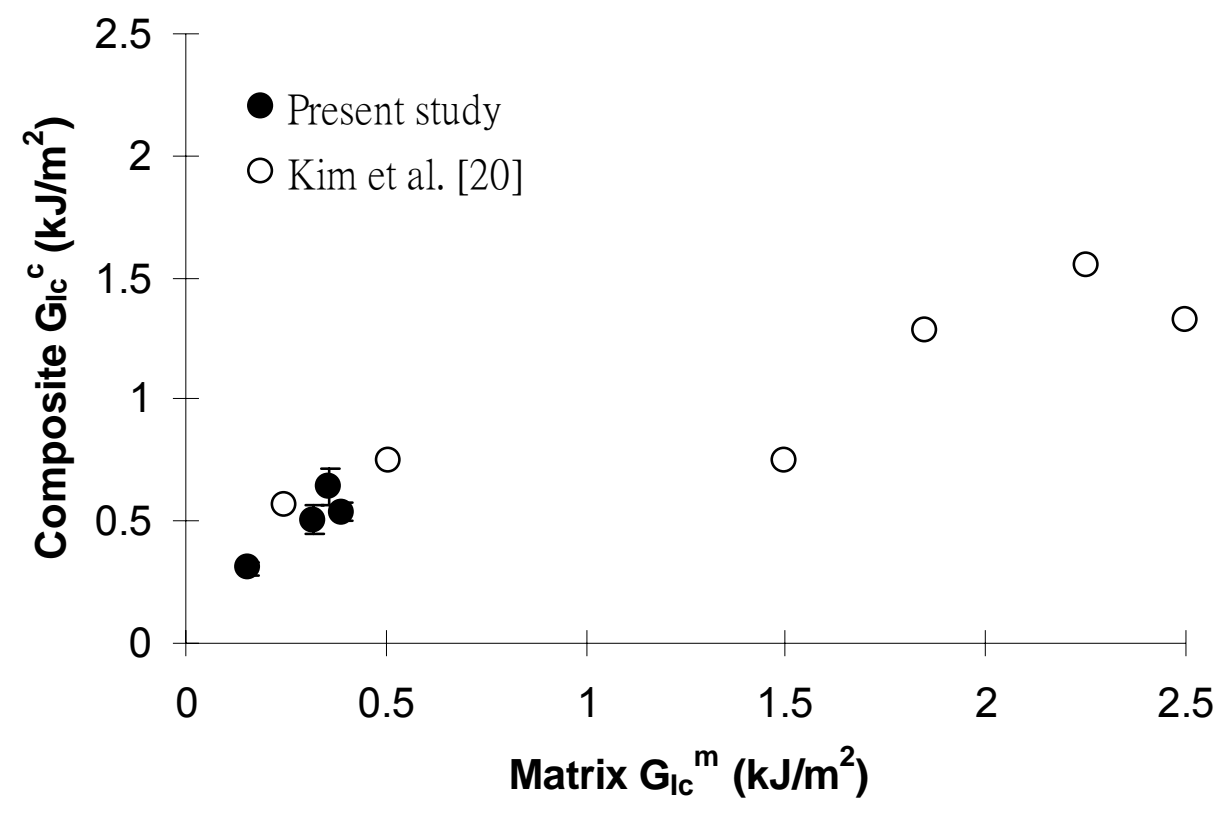

Figure 14. Correlation between the composite interlaminar fracture toughness, $\mathrm{G}_{\mathrm{IC}}{ }^{\mathrm{c}}$, and the matrix fracture toughness, $\mathrm{G}_{\mathrm{IC}}{ }^{\mathrm{m}}$. 